Conclusion In our TB population, the requirement for ICU care was infrequent, with respiratory failure being the most common indication. ICU and overall hospital length of stay was prolonged, but with a majority of patients surviving to discharge. Possible markers of a poor outcome include age, and a requirement for cardiovascular/renal support. These markers and TB-related factors now need to be explored in a larger cohort.

\section{P191 REDUCING THE CARBON FOOTPRINT IN A REGIONAL LONG TERM VENTILATION SERVICE WITH THE USE OF REMOTE MONITORING}

R Moses, C Taylor, S Wood, A Vyas. Lancashire Teaching Hospitals, Preston, UK

\subsection{6/thoraxinl-2016-209333.334}

Introduction There is strong emerging evidence on the devastating effect of anthropogenic climate change on lung health. In England, the NHS accounts for $30 \%$ of the public sector carbon footprint, with patient travel being accountable for $8 \%$ of overall travel (17\%). The climate change act (2008) resulted in the government and NHS committing to an $80 \%$ reduction in carbon emissions by 2050 .

Methods There are many studies detailed the benefit of telemonitoring in reducing carbon footprint within NHS services. Within the Lancashire and South Cumbria Long Term Ventilation Service (LSCLTVS) we have invested in a ventilator remote monitoring system (EncoreAnywhere ${ }^{\mathrm{TM}}$ ). Over a 3 month time period we analysed the telephone consultations of all 138 patients under the care of the LSCLTVS (80 patients on remote monitoring systems). Patients or carers that called reporting deterioration in a clinical condition that could not be rectified over the telephone were identified. The normal intervention that would follow would be a visit from the GP or community respiratory team, hospital admission, clinic visit or home visit from the ventilation team. A ventilator review was indicated in 29 patients which would normally necessitate either a clinic visit to Royal Preston Hospital or a consultation at home. However as these patients had remote ventilator monitoring we were able to review data and make changes remotely.

Results In a 3 month time period 29 return journeys were prevented through the use of remote monitoring. This equated to $1029.3 \mathrm{~km}$ (623 miles), $249 \mathrm{kgCO}_{2} \mathrm{e}\left(0.24 \mathrm{t} \mathrm{CO}_{2} \mathrm{e}\right)^{*}$ saved over 28 hours in commuting time and $£ 255$ in mileage costs (40 p per mile). It also had a positive impact on patient experience and no hospital admissions or clinic visits were necessary after remote consultation. $62 \%(n=18)$ patients required use of rescue packs including antibiotics and mucolytics as well as remote ventilator changes.
*Emission factors from DEFRA 2012 show for an average petrol car the value is $0.24234 \mathrm{~kg} \mathrm{CO}_{2}$ e per $\mathrm{km}$

Discussion The use of remote monitoring within the LSCLTVS has reduced the carbon footprint of the service on average $6.6 \mathrm{~kg}$ $\mathrm{CO}_{2} \mathrm{e}$ per patient. Patients also reported improved satisfaction and compliance.

\section{P192 IMPROVING OUTCOMES FOR PATIENTS WITH RESPIRATORY FAILURE USING PROTOCOL BASED CARE PLANS FOR NIV (NON-INVASIVE VENTILATION) AND HFNO (HIGH FLOW NASAL OXYGEN)}

AW Werpachowska, RO O'Leary, MK Kimberley, FA Archer, CM Maquire, ID Du Rand. Wye Valley NHS Trust, Hereford, UK

\subsection{6/thoraxjnl-2016-209333.335}

Introduction and objectives Respiratory failure is a common clinical problem and a number of treatment options are available. NIV is an established treatment for hypercapenic type two respiratory failure (RF). High Flow Nasal Oxygen (HFNO) is an alternative to standard oxygen or CPAP, and its use in hypoxemic patients has been growing.

NHS adheres to evidence based guidance and protocols to improve the safety, quality and consistency of care. We developed and implemented local guidance and protocols for managing respiratory failure with HFNO and NIV in a District General Hospital.

Methods A retrospective analysis of data from inpatient type 2 respiratory failure and NIV prior and post BTS Guideline based local protocol implementation was collected. Analysis was done to assess adherence to protocol and compare quality care and outcomes with data prior to implementation. For type 1 respiratory failure a literature review was done, evidence appraised and local guidance and protocol for HFNO developed and a pilot study conducted.

Results Since introduction of NIV proforma: NIV more frequently initiated in appropriate setting. Compliance with recommended ABG monitoring improved from $85 \%$ to $100 \%$. Documentation of escalation plans improved from 50\% to $100 \%$ (Figure 1).

HFNO was successfully implemented and commenced in our Trust over 10 weeks. All patients on HFNO tolerated therapy. Prevented ITU admission in $80 \%$ of cases selected for monitored ward based care of respiratory failure.

Conclusions In the present study, we showed how to safely implement evidence based local guidance and protocol based care plans for managing type 1 and 2 respiratory failure in a DGH to

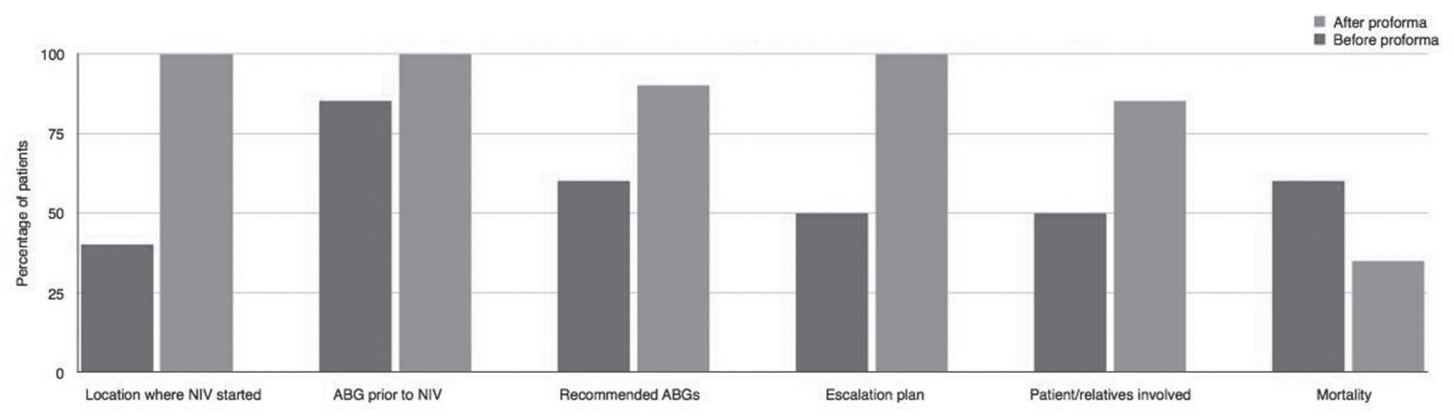

Abstract P192 Figure 1 Data comparison: documentation and mortality before and after introducation of NIV proforma 